\title{
CONSTRUÇÕES IMPESSOAIS NA ESCRITA ACADÊMICA: UM ESTUDO DAS CONSTRUÇÕES COM “SE” EM UM CORPUS FORMADO POR ARTIGOS CIENTIIFICOS*
}

\author{
Fernanda Beatriz Caricari de Morais ${ }^{1}$
}

\begin{abstract}
Resumo
Este artigo analisa as construções com o clítico se utilizadas como recurso de impessoalização em artigos científicos de diferentes áreas do conhecimento. Com base na Linguística SistêmicoFuncional, as construções encontradas foram analisadas, procurando descrevê-las com base nos contextos em que ocorrem. As ocorrências foram obtidas através do uso de ferramentas computacionais que possibilitam o trabalho com grande número de textos. As análises revelam que os usos do clítico podem ser descritos em três categorias: se em construções médias, se em construções com desfocamento de participante e se em construções agnatas.
\end{abstract}

Palavras-chave: Clítico ‘se’; Linguagem Acadêmica; Linguística Sistêmico-Funcional.

\section{Abstract}

This article analyses the constructions with clitic se used as a impersonal resource in scientific articles. According to the Systemic-functional perspective, the constructions found were analyzed, describing based on the context use. The constructions were obtained by the use of a computer program that can be used with a large number of texts. The analysis shows that se occurs in three categories: in middle constructions (self-caused process); in constructions that defocus participants, and in agnate constructions.

Key-words: Clitic 'se', Academic Language; Systemic Functional Linguistics

\section{Introdução}

Este artigo é fruto da pesquisa de doutorado (Morais, 2013) que objetivou analisar como as construções com o clítico se são utilizadas como recurso de impessoalização em artigos científicos de diversas áreas do conhecimento.

As construções analisadas com se foram às ligadas à impessoalidade, ao desfocamento de agente (em termos sistêmico-funcionais, o Ator, o Dizente, o Existente, etc.), bem como a sua renúncia no texto ou em descrições (em construções relacionais e existenciais); buscandose as implicações nos textos e suas funções nas diferentes seções dos artigos científicos.

A impessoalidade pode ser explicada como um fenômeno característico da linguagem científica, que prima em ser sintética e com foco nas ações, nos processos que envolvem as pesquisas e não em quem as fizeram. Isso explica a relação de modéstia em que o autor se coloca no texto, exigência do gênero e da linguagem. O desfocamento também ocorre quando não é importante mencionar pesquisadores da área, o que não prejudica a compreensão do texto.

\footnotetext{
* Gostaríamos de agradecer à Capes (Coordenação de Aperfeiçoamento de Pessoal de Nível Superior) pelo financiamento dos anais da VII Escola Brasileira de Linguística Computacional e do XIII Encontro de Linguística de Corpus, processo $\mathrm{n}^{\circ}$ 3472/2015-87.

${ }^{1}$ Doutora em Linguística Aplicada e Estudos da Linguagem (PUC-SP); Professora Adjunta do Departamento de Ensino Superior do Instituto Nacional de Educação de Surdos (INES/MEC), Rio de Janeiro-RJ, Brasil. Atualmente, realiza estágio pós-doutoral no Programa de Pós-Graduação em Linguística Aplicada e Estudos da Linguagem (PUC-SP), sob supervisão da Profa. Dra. Leila Barbara. Bolsista PDJ/CNPq. Email: fernandacaricari@ gmail.com.
} 
Muitos dos estudos sobre o clítico se, em língua portuguesa, estão ligados às discussões sobre a diferenciação entre-índice de indeterminação do sujeito e partícula apassivadora. Segundo as gramáticas tradicionais da língua portuguesa, o se deve ser classificado como partícula apassivadora, quando acompanhado de verbo transitivo direto, tendo sujeito definido simples, que deve concordar com o verbo que se encontra na voz passiva sintética, ou índice de indeterminação do sujeito, quando acompanhado de verbos intransitivos, transitivos diretos ou de ligação, que devem ser empregados na terceira pessoa do singular.

Por se tratar de uma análise puramente formal, não possui explicações funcionais que levem em consideração questões semânticas. Construções como Vende/compra-se casas são consideradas incorretas gramaticalmente, segundo livros didáticos e gramáticas tradicionais. Estudiosos como Nunes (1991), Monteiro (1994), Bagno (2000) e Camacho (2002, 2003) constataram que elas ocorrem com frequência tanto em linguagem popular como culta.

Para analisar as construções com se, utilizou-se o corpus do projeto $\mathrm{SAL}^{2}$ (Systemics Across Languages), formado por 1225 artigos científicos escritos em língua portuguesa, coletados aleatoriamente do Scielo, plataforma digital que contém periódicos nacionais bem avaliados pela Qualis ${ }^{3}$.

Esse corpus foi submetido ao tratamento computacional possibilitado pelo programa WordSmith Tools 5.0 (Scott, 2008) e suas ferramentas, entre as quais a mais usada é o Concordanciador, que organiza os dados a partir de um termo selecionado permitindo o estudo sistemático dos diferentes contextos em que o clítico se ocorre.

As listas de concordância foram analisadas qualitativamente com base na Linguística Sistêmico-Funcional, proposta por Halliday $(1985,1994)$ e Halliday \& Matthiessen (2004), que têm como foco a língua em uso, permitindo analisar as escolhas gramaticais feitas pelo autor em um texto (escrito ou falado) com base no ambiente situacional e cultural. Esta teoria possibilita analisar a linguagem dos textos através de fatores que dão forma a uma situação de comunicação definida por três variáveis: campo (atividade social envolvida), relações (natureza da conexão entre os participantes) e modo (forma de transmissão da mensagem). Essas variáveis são realizadas pelas 3 metafunções da linguagem: ideacional, interpessoal e textual, respectivamente.

Esta pesquisa parte da análise de textos reais para descrever o funcionamento de um clítico complexo da Língua Portuguesa que tem sido objeto de muitos estudos como os mencionados. Dentre eles, ainda não foi encontrado nenhum baseado em uma análise minuciosa de textos produzidos em situação real de comunicação, com o uso de ferramentas computacionais e de metodologia qualitativa da Linguística Sistêmico-Funcional.

Espera-se que a discussão contida neste artigo levante recursos para auxiliar professores na elaboração de materiais que facilitarão o desenvolvimento da escrita de textos acadêmicos e outros que utilizam recursos impessoais.

\footnotetext{
${ }^{2}$ O projeto SAL (Systemics Across Languages) é desenvolvido em parceria com pesquisadores da China, Argentina, México e Tailândia que procuram entender as características específicas e universais que partilham as línguas.

${ }^{3}$ A nota Qualis é uma classificação feita pela CAPES dos veículos utilizados pelos programas de pós-graduação para a divulgação da produção intelectual de seus docentes e alunos, cujo objetivo é atender às necessidades específicas da avaliação da pós-graduação realizada por esta agência.
} 
Primeiramente, os princípios da Linguística Sistêmico-Funcional são apresentados e os estudos sobre o clítico se em língua portuguesa são discutidos com base em suas especificidades. A seguir, os procedimentos metodológicos utilizados são descritos para que as categorias de análise sejam apresentadas com base nas ocorrências encontradas nos textos analisados.

\section{A abordagem Sistêmico-Funcional da linguagem}

A abordagem sistêmico-funcional da linguagem, conforme proposta de Halliday, propõe que os estudos da linguagem sejam vistos como um evento interativo, como um processo, uma troca social de significados, em contextos específicos de situação. Conforme a teoria, a análise do discurso contribui para a compreensão do texto, visando mostrar como e por que o texto transmite significado da maneira como o faz, e também se relaciona com a avaliação do texto, procurando mostrar por que o texto é ou não efetivo para os seus propósitos (HALLIDAY, 1994, p. 15).

Halliday (1994, p. 16) argumenta que uma análise do discurso não baseada em gramática não é uma análise completa, mas um simples comentário sobre o texto. A realização de um texto acontece através das relações semânticas e gramaticais. A gramática é requerida por fornecer uma compreensão clara do sentido e da efetividade de um texto, por isso precisa ter esta orientação semântica e funcional.

Na Linguística Sistêmico-Funcional (LSF), funcionalidade significa ser baseada no significado e, o fato de ser gramática é entendido como a interpretação das formas linguísticas. Por isso, a gramática separa as possíveis variáveis e aponta suas possíveis funções para podemos dar a nossa interpretação de um texto tanto pela sua descrição semântica, como pelas características linguísticas.

A linguagem é vista como prática social, cujo uso motiva-se por uma finalidade. Nessa perspectiva, a LSF estuda as maneiras pelas quais as pessoas utilizam a linguagem para atingir determinados objetivos em situações específicas dentro de uma sociedade (HALLIDAY, 1985, p. 4). A linguagem é vista como um recurso usado pelos seres humanos para criar significados.

Quando um texto (oral ou escrito) é produzido, são realizados três tipos de significado simultaneamente. Significados relativos à representação da experiência através da língua; significados relativos às representações de poder e solidariedade, atitudes em relação ao outro e os papéis sociais assumidos e significados relativos à organização do conteúdo da mensagem, relacionando o que se diz ao que foi dito. Na LSF, cada um desses tipos de significado está relacionado a uma metafunção da linguagem ideacional, interpessoal e textual (HALLIDAY, 1985, 1994, 2004).

A metafunção ideacional, também chamada experiencial, expressa o que está acontecendo no mundo externo (eventos) ou interno (pensamentos). Estuda a oração como representação, ou seja, estuda-a como um meio de representar padrões de experiência e reflete como o usuário fala sobre as ações, as situações, estados, crenças e circunstâncias. A oração, nesta perspectiva, possibilita ao falante, através das escolhas dos processos (ações), dos participantes (pessoas ou coisas) e das circunstâncias, expressar-se perante o mundo.

A linguagem é, também, utilizada para construir significados interpessoais, ou seja, os significados sobre as relações com outras pessoas e atitudes em relação a elas. Simultaneamente à organização como mensagem, a oração também está organizada como um evento interativo, envolvendo falante, ou escritor, e os seus interlocutores. No ato da fala, o falante/escritor adota para si um papel de fala e, assim, atribui ao ouvinte/leitor um papel complementar que ele quer que este adote. (HALLIDAY, 1994, p. 68). 
A metafunção textual estuda a mensagem e se realiza pela estrutura temática. $\mathrm{O}$ sistema temático dá à oração o seu caráter como mensagem. (HALLIDAY, 1994, p. 37). Esta metafunção usa a linguagem para organizar significados experienciais e interpessoais num todo coerente e linear. Em um texto, esta função reflete-se na escolha da posição de uma informação dada ou nova na sentença.

Sobre o tema desta pesquisa, sabe-se, com base nas análises feitas durante a pesquisa de doutorado, que o clítico se é um fenômeno da língua portuguesa com implicações em vários níveis. Além da implicação textual, ao tratar da organização da mensagem através das escolhas temáticas. Há, também, implicações interpessoais, relacionadas às interações e intenções dos interlocutores na comunicação. Os usos desse clítico se estão intrinsecamente relacionados à transitividade e à presença ou realização ou não do Agente (que tem a ver com voz e, portanto, com modo verbal); assim agentividade, da metafunção ideacional e voz, da metafunção interpessoal, terão também papel importante na análise. Dessa forma, as metafunções são utilizadas em conjunto, como apoio para analisar e compreender os usos desse clítico em artigos científicos. Na LSF entende-se que simultaneamente à organização da mensagem, a oração também está organizada como um evento interativo, envolvendo falante, ou escritor, e os seus interlocutores.

\section{Estudos sobre o clítico se em língua portuguesa}

Esta pesquisa se apoiou em estudos realizados sobre aspectos do clítico se em diversas áreas da Linguística, como Ikeda (1977), Camacho (2002, 2003), Nunes (1991, 1995, 1996), Monteiro (1994) e Bagno (2000) e outros que contribuíram para a discussão dos usos do se.

A primeira pesquisadora acima analisa as funções do $s e$ índice de indeterminação do sujeito e partícula apassivadora, aponta os entraves no ensino e no emprego desta partícula e propõe que o se, no português brasileiro (PB), constitui sempre indeterminação, não importando a predicação do verbo.

Camacho (2002) estuda os tipos de construção de voz no PB, que segundo o pesquisador, preenchem uma diversidade de valores semântico-oracionais e pragmáticodiscursivo, codificados na sintaxe por diferentes tipos de configurações estruturais. Em sua pesquisa, ele discute os tipos de voz com o se, como a passiva, a impessoal, a reflexiva, a reflexiva-recíproca e a média, demonstrando a instável distinção entre essas construções. Em seu trabalho seguinte, Camacho (2003) trata, em maiores detalhes, a voz média, recurso disponível na LP, formalmente identificados pelo uso das referências anafóricas através do uso do $s e$.

Seguindo a linha de pesquisa proposta por Tarallo e Kato (1989), Nunes (1991, 1995, 1996) procura rastrear o percurso diacrônico do se apassivador no PB. Nunes, assim como Monteiro (1994), constata o que Naro (1976) observa: o se passivo precede o se indeterminador, que é relativamente recente. Nunes compara o PB ao Português Europeu (PE) ao observar que em relação às construções com verbos transitivos, o PE falado praticamente se mantém estável em relação à variação provocada pelo surgimento do se indeterminador, tendo, assim, no PE moderno, uma preferência pela construção com o se apassivador, diferentemente do PB, que se distingue por oposição a essa tendência. Cada vez mais, o PB mostra a sua preferência pelas construções inovadoras, afastando-se do PE.

A concordância em construções com o se reflete mais um aspecto da modalidade escrita da língua do que propriamente algo do domínio nacional. Nunes $(1991,1995)$ hipotetiza que o surgimento do se indeterminador foi desencadeado por um processo de reanálise sintática da antiga construção com se apassivador. 
Estudando exemplos do NURC, corpus do Projeto de Estudo da Norma Urbana Culta, Monteiro (1994) discute que o se em enunciados como "morre-se de fome", "aluga-se esta casa" e etc. não pode ser considerado apassivador, pois o clítico sugere na consciência de qualquer falante que alguém morre ou aluga. $\mathrm{O}$ pesquisador argumenta que, para muitos estudiosos, o clítico se deve ser interpretado como um recurso que a língua dispõe para marcar a indeterminação.

A interpretação passiva das construções com se, conforme discute Monteiro (1994), parece ter sido mais um equívoco da tradição gramatical. Bagno (2000) propõe que as construções tradicionalmente chamadas de passivas sintéticas não são passivas e discute os equívocos e preconceitos da análise normativista feita pelo que ele chama de "comandos paragramaticais" e propõe uma nova postura a ser adotada pelos professores de LP em relação a essas particularidades. $\mathrm{O}$ autor destaca o caráter nominativo do se, atribuindo seu apagamento nas orações em que o sujeito (-animado) pratica uma ação que incide sobre si mesmo, como em "a porta se fechou" e "o vaso se quebrou".

Os estudos descritos acima são de fundamental importância para a análise e a comparação dos usos do clítico se em artigos científicos. Os procedimentos de análise, bem como os usos da ferramenta computacional WordSmith Tools (ScOTT, 2008) são detalhados no item seguinte.

\section{O percurso de análise}

O instrumento computacional utilizado em Linguística de Corpus (LC), WordSmith Tools (Scott, 2008), possui ferramentas úteis para a análise de vários aspectos da linguagem. Uma das ferramentas, a lista de palavras (Wordlist), é utilizada para organizar os corpora em listas que são ordenadas alfabeticamente e por frequência. Com essa mesma ferramenta, podem-se obter dados estatísticos dos textos, como: número de palavras (Tokens), número de palavras diferentes (Types), número de orações (Sentence), etc., contribuindo tanto para a organização dos dados estatísticos, como para a análise das palavras utilizadas com mais frequência.

Com a ferramenta Concord, podem-se observar os contextos em que a palavra de busca ocorre através do concordanciador. Nesta ferramenta, a palavra de busca aparece destacada e no centro da tela do programa do texto em que ocorre. Através das listas de concordância é possível estudar o contexto de ocorrência da palavra de busca (o clítico 'se') simultaneamente em todo o corpus.

Foram feitas listas de concordância com os artigos científicos, com o uso da ferramenta concord. Foram eliminadas as ocorrências em que o se é uma conjunção, com valor condicional, como no exemplo:

1. $\quad \underline{S}$ verificarmos as diferenças nas duas situações, ou seja, subtraindo-se o número médio de palavras por minuto em pares do número médio de palavras por minuto do teste individual, observamos .... (Delta026).

Casos como esses, em que a substituição do clítico por uma das outras conjunções de mesma função não altera o significado, estão claramente explicitados em gramáticas da língua portuguesa e em livros didáticos. Além de seus usos não serem ligados à impessoalidade, desfocamento de um participante (Ator, Dizente, Existente, etc.), bem como à renúncia do autor no texto, isto é, quando o autor descreve algo sem se representar no texto. Outro uso amplamente descrito em gramáticas são as construções reflexivas em que se funde, na mesma entidade, iniciador e ponto de chegada.

2. ... o autor se considera dirigindo o foco das atenções.... (Idg020). 
Como esses tipos de construções possuem sujeito e o clítico não possui o uso ligado à impessoalidade, elas foram excluídas, posto que é o mesmo que dizer:

2'....o autor considera ele mesmo dirigindo o foco das atenções.....

Em termos sistêmicos, nessas construções o Ator se funde com a Meta da oração. A substituição do se pelo uso de si mesmo é um teste eficiente para identificar essas construções: João se cortou = João cortou a si mesmo.

Inicialmente, pensou-se em também excluir as orações em que o se altera o tipo de processo. O verbo dar, por exemplo, que quando ocorre com o clítico não tem sentido de ceder (material: dar um prêmio), mas sim de ser (relacional) e, também, ocorrer/acontecer (existencial):

3. O monitoramento dos sensores dá-se por meio de comparação. Toda vez que existe alteração elevada da leitura de distância realizada pelo sonar, o programa interpreta como posicionamento indevido... (c.agrárias10).

\section{3'. O monitoramento dos sensores ocorre por meio de comparação.... (Existencial) \\ 3'’. O monitoramento dos sensores é por meio de comparação.... (Relacional)}

No entanto, ao usar esse tipo de construção, o autor renuncia à oportunidade de se representar nos acontecimentos, optando por uma descrição. Os processos existenciais possuem essa característica distintiva estrutural que promove um sinal de renúncia, segundo Thompson (1996, p. 101), podendo ser visto como um recurso que o autor utiliza para apenas observar, ao invés de participar do fluxo informacional do texto. De certa forma, na construção equivalente - relacional, o autor também renuncia a sua participação e apenas descreve o monitoramento dos sensores. Se o autor tivesse escolhido a construção passiva (analítica), haveria um resquício de sua participação.

Após as exclusões das construções reflexivas e condicionais, o instrumental usado como ponto de partida para entender os usos do clítico se foi a busca por construções com significado próximo, testes através de refraseamentos das ocorrências permitiram agrupá-las em grupos específicos:

\begin{tabular}{|l|l|l|}
\hline Grupos & Construções permitidas & Exemplos \\
\hline 1 & Relacional e/ou Existencial; & $\begin{array}{l}\text { Este modo de pensamento se acha livre do } \\
\text { princípio de realidade"... (25430). }\end{array}$ \\
\hline 2 & $\begin{array}{l}\text { Passiva analítica e primeira } \\
\text { pessoa do plural; }\end{array}$ & $\begin{array}{l}\text { Observa-se que houve diferença } \\
\text { significativa.... (25960). }\end{array}$ \\
\hline 3 & Primeira pessoa do plural; & $\begin{array}{l}\text { Entretanto, hoje sabe-se que esse problema } \\
\text { causado pela presença da bactéria Xylella } \\
\text { fastidiosa... (25744). }\end{array}$ \\
\hline 4 & Passiva analítica e estativa; & $\begin{array}{l}\text { Este trabalho se organiza do seguinte } \\
\text { modo: a seção 1 apresenta motivações } \\
\text { semânticas e pragmáticas.... (Idg001). }\end{array}$ \\
\hline
\end{tabular}




\begin{tabular}{|l|l|l|}
\hline 5 & Construção sem o clítico se. & $\begin{array}{l}\text { A dificuldade de se trabalhar com este } \\
\text { modelo reside no fato de que os modelos } \\
\text { de apreçamento baseados no conceito da } \\
\text { Medida Martingal Equivalente (MME) não } \\
\text { são viáveis.... (econ030). }\end{array}$ \\
\hline
\end{tabular}

Quadro 1: Agrupamento inicial de acordo com os testes feitos.

No primeiro grupo, concentram-se certos verbos materiais, mentais ou verbais que quando ligados ao se adquirem características de processos diferentes (existenciais e/ou relacionais). Pode-se notar que, no exemplo A do quadro, o verbo achar não tem significado material como sinônimo de encontrar, mas sim relacional:

A'. Este modo de pensamento está livre do "princípio de realidade" e está em relação direta com o "princípio de prazer".

No grupo 2, concentram-se os verbos de vários tipos, principalmente, materiais que, quando ocorrem com se, em construções sem Agente (Ator, Dizente, Experienciador, etc.), há uma participação pressuposta. Nota-se que o exemplo 6 pode ser refraseado para a passiva (analítica) e para a primeira pessoa do plural:

B'. Observamos que houve diferença significativa quando se contrastaram os grupos de testemunhas e clones nos três locais.

B'. Foi observado que houve diferença significativa quando se contrastaram os grupos de testemunhas e clones nos três locais.

Nos eventos representados pelas orações acima, pressupõe-se a existência de um participante (Ator, Dizente, Experienciador, etc.). Admitir o sentido passivo, segundo Said Ali (1966/2008, p. 116), é admitir a possibilidade de um Agente. Por isso pode-se dizer que, em construções deste tipo, o clítico é um mecanismo importante para apagar o autor no texto, deixando, porém, um resquício de sua participação.

No terceiro grupo, estão alguns verbos mentais e verbais que se comportam de forma diferente, pois não aceitam serem construções equivalentes dos tipos relacionais e/ou existenciais e, também, não permitem refrasear para a passiva com o auxiliar ser (passiva analítica). A construção com significado mais próximo é a primeira pessoa do plural, porém esse uso parece ser genérico e universal, como apontam estudos descritos em outras línguas, em especial, o espanhol e o italiano (DE Miguel, 1992 E Cinque, 1988).

Como se pode observar, a passiva analítica gera uma construção que não é bem aceita pela comunidade discursiva, pois no corpus não há nenhuma ocorrência com é sabido. Assim, só é possível refrasear para a primeira pessoa do plural, porém o significado não é o mesmo, pois se pressupõe a inclusão do autor: Xylella....

C*. Entretanto, hoje é sabido que esse problema é causado pela presença da bactéria

C'. Entretanto, hoje sabemos que esse problema é causado pela presença da bactéria Xylella....

A circunstância de tempo hoje permite pensar que os participantes de saber (Experienciador) sejam pesquisadores da área a qual esses artigos pertencem e que a informação dada é compartilhada por esses pesquisadores. Dessa maneira, acredita-se que as escolhas léxico-gramaticais e, principalmente, o contexto em que ocorrem são de fundamental importância na compreensão do significado do se. 
No penúltimo grupo se concentram as construções que representam os eventos como autosuficientes, ou seja, eles parecem acontecer por si mesmos e a responsabilidade do evento é exterior à entidade afetada. Como se pode observar no exemplo 8, a autosuficiência do evento é a principal característica dessas construções. Dessa forma, o autor se exime da culpa, se distancia do texto, evitando assim seu comprometimento. Muitas vezes, a ação não foi praticada pelo autor, mas quem a praticou não é importante para ser mencionado no artigo. A construção D pode ser refraseada para estativa:

\section{D'. Este trabalho está organizado do seguinte modo...}

A equivalência com a passiva é aceitável nessas construções, porém o significado é diferente. Na passiva, se pressupõe um participante (Ator, Experienciador ou Dizente), enquanto a estativa tem o caráter de acontecer por si só, conforme discute Camacho (2002). Para ele (op.cit.), essas construções passam por um processo de detransitividade, em que o Agente (Ator, Experienciador ou Dizente) está suprimido, não há seu resquício na oração.

É importante observar que um evento causativo, como as construções acima, exclui a construção reflexiva, pois o se naquelas construções não pressupõe um esforço a si mesmo, mas por si mesmo, o que leva a interpretá-las como construções espontâneas.

As construções do último grupo se comportam diferente dos demais, pois não possuem nenhuma construção equivalente. No entanto, se o clítico for retirado não há alteração de significado, como se pode observar no exemplo E do quadro acima.

\section{A proposta para o ' $S E$ ' em Língua Portuguesa}

Com base na organização das ocorrências em cinco grupos, descritos no quadro 1, verificou-se que três deles partilham semelhanças no que diz respeito ao desfocamento de participante, são eles: 2, 4 e 5 .

$\mathrm{Na}$ verdade, esses grupos tratam do mesmo fenômeno: o apagamento, o encobrimento da identidade desses participantes que pode ser explicada pela relação de modéstia que os autores se colocam no texto, exigência do gênero e da linguagem. Possivelmente, esse desfocamento se dá quando não há importância de se mencionar pesquisadores da área, por exemplo, o que não prejudica a compreensão do texto que tem como foco os processos, as ações de fazer pesquisa e não em quem a faz, conforme apontam pesquisadores desse gênero (HALlidAY, 2004; HaLliday \& MARTIN 1993; SWALES E FEAK 1999).

Esses cinco grupos apresentados acima possibilitaram a criação de três categorias: 


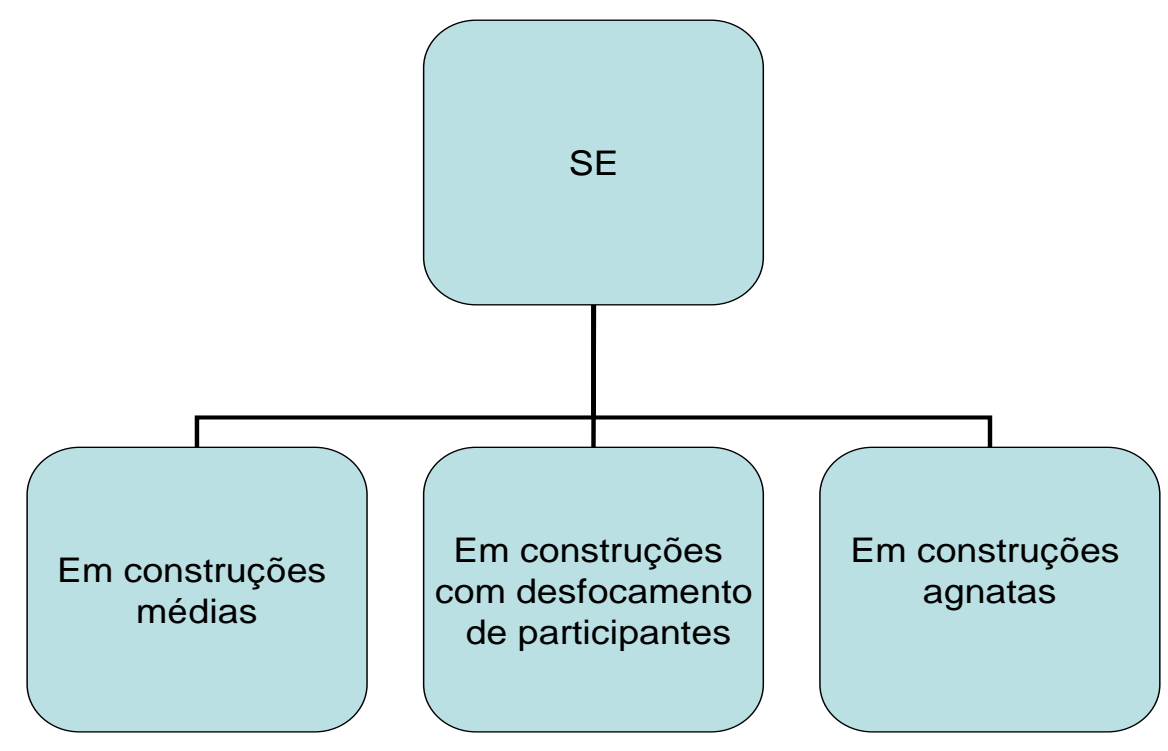

Figura 1: Categorias de uso do clítico se.

Para facilitar a análise, foi usada a coluna set, nas listas de concordância do programa WordSmith Tools (SCOTT, 2008). Essa coluna permite a inserção de números correspondentes ao grupo as quais as ocorrências pertencem e que foram alterados ou ampliados conforme os dados iam sendo analisados e as categorias divididas ou inseridas. Assim as ferramentas do referido programa auxiliam a análise quantitativa e qualitativa, fornecendo detalhes sobre o se em seus contextos de ocorrências, permitindo generalizações que se tornam cada vez mais confiáveis. Como já tem sido verificado em grande número de pesquisas como aquelas ligadas aos projetos SAL, a Linguística de Corpus fornece um suporte metodológico adequado às pesquisas que utilizam a Linguística Sistêmico-Funcional, por também trabalhar dentro de uma visão de linguagem enquanto sistema probabilístico (BERBER-SARDINHA 2004:34).

A seguir, as categorias de análise são apresentadas com base na análise das ocorrências do corpus de estudo.

\subsection{Categoria 1 - SE em construções médias}

Nesta categoria, são analisadas as construções com verbos que, quando ocorrem com o clítico se, aparentam uma ausência de Agente, dando a impressão de que a ação aconteceu sozinha, sem a influência de um participante (Ator, Dizente, Experienciador, etc.), como na construção a seguir:

A. ... a sociologia estética se divide em três capítulos.... (25289).

Segundo os pressupostos de Halliday (1985, p. 147), as construções que representam um processo autocausado (self-caused process), sem o Agente, são chamadas de médias, nas quais o núcleo da estrutura experiencial é Processo + Meio (a sociologia), ou seja, nelas o Meio é o único participante.

Nas construções médias, segundo os pressupostos da Linguística SistêmicoFuncional, há uma clara impessoalização no processo. $O$ item lexical em posição de participante (inanimado) é representado como se fosse o responsável pela ação. 
Caffarel (2006) analisou artigos de jornal em francês e constatou que as orações passivas possuem participantes omitidos e as orações médias apresentam participantes inanimados, fato que ocorre também em artigos científicos, gênero em que essas construções contribuem para o afastamento total do autor por meio de uma construção em que não há resquícios de sua participação.

No mundo real, há sempre uma causa externa, isto é, alguém ou pessoas responsáveis por determinada ação. Assim, se pode pressupor que a construção transitiva equivalente a A seria:

B. O autor dividiu a sociologia estética em três capítulos....

C. A sociologia estética foi dividida em três capítulos....

Em B, há um Ator (autor) expresso que age sobre uma Meta (a sociologia). A interpretação transitiva é linear e a função que pode ser definida pela extensão da Meta (processos materiais), Alvo (processos verbais) ou Fenômeno (processos mentais). Na oração C, há uma oração passiva sem Agente explícito, cuja participação está pressuposta.

Os usos das ocorrências encontradas no corpus de estudo estão ligados à descrição, representando ações que, por não terem explicitado o participante Agente, parecem ter ocorrido sem ele, como as mencionadas abaixo:

1. A presente pesquisa se desenvolve nessa linha, com intenção de contribuir para o entendimento do crescimento facial....(odrdp14.1).

2. A modernização explica-se porque, ao se tornarem democracias, esses dois países passaram a sofrer pressão de grupos sociais para compensar suas dividas históricas com grupos excluídos (cf. Telles, 2004). (25280).

Nessas ocorrências, tem-se a impressão que as ações ocorrem sem Agente, ou podem ser ações em que o possível Agente é escondido pelo elemento se, ou ainda, o elemento se em posição de sujeito pode representar um possível Ator ou Dizente.

Em muitas construções, pode-se pressupor que, nas orações transitivas, os atores seriam os autores/pesquisadores, mas optaram por focalizar o trabalho e não suas participações:

3. $O$ objetivo deste artigo é revelar como se desenvolveu essa pesquisa e levantar questões relativas ao comportamento desses jovens.... (25362).

4. O presente estudo se baseou na comprovação da eficácia da ONC para a realização da metodologia.... (odrdp8).

5. A presente pesquisa se desenvolve nessa linha, com intenção de contribuir para o entendimento do crescimento facial .... (odrdp14.1).

A escolha dos Meios (pesquisa, presente estudo e presente pesquisa) contribui para a apresentação do tipo de pesquisa realizado e eles permitem a elaboração de pares transitivos, conforme proposta de Halliday (2004, p. 289), em que os Atores são os pesquisadores dos artigos:

3'. O objetivo deste artigo é revelar como desenvolvi/desenvolvemos essa pesquisa e levantar questões relativas ao comportamento....

4'. Baseei/Baseamos o presente estudo na comprovação da eficácia da ONC para a realização da metodologia....

5'. Desenvolvo/Desenvolvemos a presente pesquisa nessa linha.... 
da pesquisa:

As construções médias são utilizadas, muitas vezes, na descrição dos resultados (25729).

6. No experimento A, thiodicarb se destacou em relação à testemunha e fipronil.

7. Devido ao teor de K no solo (1,5 mmolc dm-3) estar em nível baixo (SILVA e RAIJ, 1996), considerando a época tardia de instalação do experimento e ainda o clima desfavorável durante o ciclo, o algodoeiro não se desenvolveu adequadamente. (25522).

8. A correlação entre as estimativas dede h2 foi baixa, indicando que a estimativa da contribuição dos locos em heterozigose não se caracterizou como bom indicador da variabilidade potencial da população. (25929).

9. Dessa forma, a sinonímia textual se adequa à definição de sinonímia proposta por Câmara Jr. mencionada acima.... (Igd063).

Ao optar por essas construções, os autores colocam em posição temática informações já dadas, avaliando-as com base nos experimentos realizados, criando construções intransitivas. Um tipo de uso do clítico se ocorre com a utilização de orações relacionais (categoria 3 - se em construções agnatas), porém com significado diferente, uma vez que, na oração relacional, uma qualidade ou uma característica semelhante é atribuída a uma entidade, o participante não tem status de Agente, não agindo sobre um outro participante. Assim, nessas construções, o participante (Meio) está em posição de sujeito e parece estar envolvido na ação, mesmo sendo um participante inanimado.

Outro tipo de construção média também ocorre no corpus para representar os resultados da pesquisa:

10. Além disso, as perdas não se relacionaram ao uso ou não da assistência de ar. (25736).

11. O índice de colheita também se relacionou de forma positiva com a eficiência de uso (Pg/Ns) nas variedades Caiano $(r=0,83 *)$, BR $105(r=0,81 *)$, Nitrodente $(r=0,87 *)$, Carioca $(r=0,95 * *)$, Antigo Maya $(r=0,99 * *)$ e Catetão $(r=0,91 * *) .(25890)$.

12. A gema lateral que originará a espiga superior transforma-se num primórdio floral alguns dias após a diferenciação do pendão.... (25842).

O verbo relacionar está entre os materiais e mentais, pois pressupõe uma reflexão do pesquisador em comparar dados. Nesses exemplos, como em 10, após analisar as perdas do experimento, o autor dá suporte à sua argumentação contrastando os resultados da sua pesquisa com os de um pesquisador antecessor. Assim como em 11, em 12, há representações dos resultados como se eles tivessem se relacionado sozinhos, não havendo representação, portanto, da identidade desses pesquisadores que, com base nos dados, analisam os objetos de estudos. estudo:

Essas construções são muito utilizadas na descrição de aspectos metodológicos do

13. A amostra constituiu-se de 52,4\% de respondentes do sexo masculino e 47,6\% do sexo feminino, com idades entre 18 e 48 anos (média = 24 anos, d.p. = 5,4). (25913).

14. Esse grupo se divide entre trabalhadores que valorizam os princípios de distribuição de renda e gestão democrática..... (econ46).

15. Essa descrição se baseia na pesquisa de campo desenvolvida por mim desde 2002 junto às emissoras Globo, Bandeirantes, SBT e RedeTV!, ... (25266). 
Tanto em 13, como em 14, tem-se a descrição dos grupos pesquisados. No primeiro, os pacientes voluntários que se submeteram ao tratamento e, no segundo, os trabalhadores entrevistados na pesquisa. Em 15, apesar de haver essa descrição como Meio, há também uma passiva a seguir com o Ator expresso (por mim).

Há construções médias com processos verbais que introduzem o objetivo e o tipo de pesquisa realizada:

16. Este artigo se propõe a analisar, a partir de um levantamento histórico, como a orientação estratégica foi consolidada, considerando-se as competências organizacionais e gerenciais sob a perspectiva construtivista inspirada na abordagem da aprendizagem organizacional. (25914).

17. A partir da consideração de que o discurso se constrói a partir de gêneros discursivos que variam e se constituem nas diversas esferas de atividade humana, este trabalho se propôs a estudar o funcionamento da LIBRAS no gênero contos de fadas. (Idg043).

18. Este artigo propõe-se a analisar o papel da Académie Julian, uma academia privada que recebeu grande parte dos artistas brasileiros que aportaram em Paris entre o final do século XIX e o início do século XX. (25349).

Essas construções são utilizadas na introdução do artigo para apresentá-lo, evidenciando o tipo de pesquisa realizado e seu o objeto de estudo. $O$ uso de circunstâncias de lugar este artigo e este trabalho permitem entender que as construções transitivas teriam o autor do artigo como Dizente do processo propor.

No item seguinte, a discussão dos usos do clítico se continua com a análise da categoria 2 - se em construções com desfocamento de participante.

\subsection{Categoria 2: $S E$ em construções com desfocamento de participante}

O termo desfocamento de participante é utilizado, nesta pesquisa, para descrever as situações em o clítico se é visto pela gramática tradicional como indeterminação e voz passiva.

Para as gramáticas tradicionais da língua portuguesa como: Rocha Lima (2002), Cegalla (1996) e Cunha e Cintra (1985), o se deve ser classificado como partícula apassivadora, quando acompanhado de verbo transitivo direto, tendo sujeito definido simples, que deve concordar com o verbo que se encontra na voz passiva sintética, ou índice de indeterminação do sujeito, quando acompanhado de verbos intransitivos, transitivos diretos ou de ligação, que devem ser empregados na terceira pessoa do singular.

Há vários aspectos a considerar nessa análise, pois se trata de uma análise puramente formal, portanto não possui explicações funcionais que levem em consideração questões semânticas. Note-se que essas construções não são consideradas padrão, ou seja, são consideradas erradas, como Vende/compra-se casas, exaustivamente citadas como incorretas em livros didáticos e gramáticas tradicionais. Elas, no entanto, ocorrem com frequência tanto em linguagem popular como culta, conforme discussões de Nunes (1991), Monteiro (1994), Bagno (2000), Camacho (2002, 2003), entre outras. Said Ali (1966/2008, p. 103-106) já tratava casos como compra-se o palácio, morre-se de fome como fórmulas destinadas "a calar o nome do Agente". O clítico se sugere, nesses contextos, que alguém compra, alguém morre, mas que não se conhece ou não se quer nomear. 
A análise das listas de ocorrências dos verbos mais frequentes que ocorrem com o clítico se permitiram compreender o significado e a função que este clítico desempenha nos textos. Esta compreensão não pode ser baseada na análise do verbo principal, se é transitivo direto (partícula apassivadora) ou intransitivo, transitivo direto ou de ligação (índice de indeterminação do sujeito). É preciso se atentar para as escolhas léxico-gramaticais e, principalmente para o contexto em que ocorrem, para assim compreender o significado do se que pode permitir diferentes graus de desfocamento de participante- do autor/pesquisador ou de pesquisadores da área ou, ainda, de pessoas de modo geral.

Esse desfocamento é um fenômeno muito frequente na linguagem científica que prima em ser sintética e com foco nas ações, isto é, nos processos que envolvem uma pesquisa e não em quem as fizeram (pesquisadores). Isto explica a relação de modéstia em que o autor se coloca no texto, exigência do gênero e da linguagem.

O termo desfocamento de Agente foi proposto por Shibatani (1985, p. 832) como uma função primária e não uma mera consequência da promoção do objeto/paciente. $\mathrm{O}$ autor prefere esse termo por cobrir além da demoção do Agente, supressão do Agente e Agente em segundo plano, a ausência de menção do Agente, menção do Agente sem ranhura sintática e indefinição da identidade do Agente por uso de formas plurais ou referências indiretas.

Embora não tenha estudado a língua portuguesa, Shibatani estudou as formas de desfocamento de Agente em muitas línguas como: ainu, chamorro, turco, quéchua, espanhol, francês e japonês, e discutiu a falta de atenção com as funções do desfocamento. Este trabalho visa contribuir na descrição desse fenômeno em língua portuguesa com base na proposta da referida tese (MORAIS, 2013) de que há diferentes graus de desfocamento de participante (em termos sistêmico-funcionais).

O alto grau de desfocamento ocorre quando há maior imprecisão, quando o autor não é envolvido. É um recuso de não envolvimento; qualquer participante pode estar envolvido. $\mathrm{Na}$ escrita acadêmica, não se pode ver a diferença entre os graus alto e médio, no corpus desta pesquisa, por outro lado, sabe-se que, em outros gêneros, o desfocamento pode englobar qualquer pessoa. Os exemplos abaixo foram retirados de artigos de jornais:

a. Oportuna e realista a reportagem, posto que vive-se talvez como nunca uma ditadura das crianças e dos jovens.... (Folha de São Paulo, 10 de novembro de 2012).

b. Quando se trabalha muito duro, para valer, os resultados aparecem. (Folha de Pernambuco, 31 de outubro de 2012).

Pode-se notar que o desfocamento dos exemplos acima é de alto grau, pois não se sabe quem está sendo desfocado, trata-se de uma generalização. Com base no contexto de ocorrência, é possível supor que, no primeiro exemplo, a ditadura é vivida pelos pais de crianças e adolescentes, pode se estender a todos os pais, caracterizados como submissos aos filhos. No segundo, o se desfoca os trabalhadores num todo, sem tratar de um grupo específico.

Voltando para a linguagem acadêmica, chamou-se desfocamento de grau médio quando ele cobre um grupo, em geral pesquisadores da área, inferindo-se que o autor e o leitor, sendo da mesma área, e, por isso, partilham dos mesmos conhecimentos, estejam envolvidos na ação. É importante ressaltar que, neste caso, o leigo não está incluído no desfocamento de médio grau. Enquanto o desfocamento de baixo grau ocorre quando algum elemento da oração restringe apenas o envolvimento do autor do artigo ou de um pesquisador, geralmente, colocado fora da oração entre parênteses. É possível pressupor seu envolvimento mesmo que não esteja expresso. 
Nos artigos científicos, que compõe o corpus desta pesquisa, muitas vezes são as circunstâncias ou o tempo verbal os responsáveis tanto pela restrição do desfocamento apenas do autor, como pela ampliação do desfocamento que inclui além do autor, a comunidade acadêmica. É o contexto de ocorrência que permite deduzir esses tipos de desfocamentos por via indireta.

Nas ocorrências abaixo, pode-se observar a importância do uso de certas circunstâncias na compreensão do significado do se:

1. No melhoramento genético utiliza-se autofecundação para se obter uniformidade.... (25625).

2. Com essa técnica, obtêm-se plantas haplóides, que se podem tornar férteis com a duplicação do número de cromossomos utilizando-se a colchicina. (25842).

3. $\quad$ Na região de Araucária $(P R)$, utiliza-se o sistema de corte anual em cerca de $50 \%$ da copa das plantas.... (encbnr).

As circunstâncias de modo (16 e 17) e lugar (18), nas ocorrências acima, contribuem para o significado genérico do $s e$, ou seja, nessas construções não se sabe quem utiliza ou obtém, mas se pode pressupor que sejam pesquisadores da área e que o autor esteja incluído. Naro (1976) já discutia o traço de grupo que o se pode dar às construções. O clítico se permite o desfocamento desses participantes que não são relevantes para serem mencionados no artigo científico, por isso pode-se propor chamar casos assim de desfocamento de médio grau. Podese refrasear construções como as acima como a 16':

\section{6'. No melhoramento genético os pesquisadores utilizam autofecundação....}

A passiva com o verbo ser não pode ser considerada equivalente à construção com se, apesar desses verbos ocorrerem nessa construção, o significado não é igual, pois se pressupõe a participação de um Ator, neste caso:

\section{6"'. No melhoramento genético foi utilizado autofecundação....}

Hawad (2010) estudou a possível equivalência entre a chamada voz passiva sintética e voz passiva analítica e, para esta pesquisadora, essas construções são formas distintas. O que há de comum entre elas é que ambas podem ser caracterizadas pela não identificação do Ator. A sintética, por sua vez, é uma forma de indefinição extrema das pessoas envolvidas no discurso.

No refraseamento acima, não se tem um Ator expresso, no entanto se pressupõe um Agente diferente da construção com se, que não precisa ter Ator e, dessa forma, o autor tira o foco na referência de pessoa para destacar a ação, o processo de fazer pesquisa. Uma construção com se com Ator, como a passiva com o verbo ser, é uma construção não aceitável no gênero, posto que não ocorre no corpus de estudo:

\section{6*. No melhoramento genético utiliza-se (pelos pesquisadores) autofecundação....}

O termo indeterminado pressupõe que o falante não consiga presumir quem é, de fato, o Ator do processo. No entanto, com base nas ocorrências do corpus de estudo, pode-se inferir quem são esses Atores que foram desfocados, deixados em segundo plano pelo pesquisador que, possivelmente, escolheu o desfocamento por não ser importante para o relato da pesquisa ou, ainda, por ser conhecido e partilhado na área de estudo.

O significado tradicional de sujeito indeterminado sempre acarreta o significado de Ator não-identificado ou Ator desfocado. A LSF vê os conceitos Sujeito e Ator como elementos distintos, pertencentes à metafunção interpessoal e ideacional, respectivamente. 
A conjunção quando é frequentemente utilizada nas construções com se acompanhadas de verbo no tempo presente e, também, contribuem para o caráter genérico, conforme ocorrências abaixo:

4. Quando se aplica o teste $F$ em análise de variância para a fonte de variação tratamentos com mais de um grau de liberdade, obtêm-se informações gerais, relacionadas com o comportamento médio dos tratamentos (BANZATTO e KRONKA, 1995). (25657).

5. Entretanto, quando se emprega inóculo de fungo micorrízico deve-se avaliar, com mais atenção, a quantidade e o tipo de material empregado como adubo orgânico. (25859).

6. Para avaliar o ARM desse último mês, é necessário calcular o Neg Acum do mês anterior adicionado do P - ETP do mês em curso. Essa última condição é mais comum quando se efetua o BHC ao longo de anos reais.... (25672).

Tanto em 19 e 20, há além da conjunção quando, outros verbos com se (obter e avaliar) que também possuem o uso genérico de aplicar, empregar e efetuar, estendendo o significado a qualquer pesquisador da área que efetuar os procedimentos descritos no contexto das ocorrências. Em 20, o uso do modal de alto grau deve mostra a obrigação do tipo de avaliação descrito no artigo.

Os autores poderiam optar pelo uso de nominalizações, porém a referência genérica de pessoa dada pelo desfocamento estaria perdida:

19'. A aplicação do teste $F$ em análise de variância.....

$\mathrm{Na}$ maioria das ocorrências em que o verbo principal está no tempo presente, como nas analisadas acima, o se contribui para o desfocamento de participante, mas não se sabe quem está sendo desfocado de fato. Com base nos contextos de ocorrência, pode-se pensar que sejam os pesquisadores da comunidade científica que partilham do conhecimento da área e compreendem os procedimentos descritos. Não se pode inferir se o leitor está incluído ou não nesse grupo de pesquisadores, partindo-se do princípio que o leitor e o escritor fazem parte de uma mesma comunidade discursiva (SWALES, 1990), pode-se pensar que eles podem estar incluídos nesse tipo de desfocamento de médio grau.

Ocorrências com o desfocamento de baixo grau são comuns com as circunstâncias de lugar e com o verbo no pretérito, como mostram as ocorrências abaixo:

7. $\quad$ Nesta pesquisa, optou-se pela quantificação da manta.... (eng.san.5).

8. Nessa pesquisa verificou-se valor de produção de matéria seca para o milheto

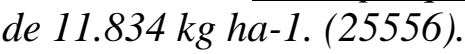

9. Nesse trabalho não se identificou nenhum híbrido SO intrapopulacional superior à média dos híbridos comerciais utilizados como testemunhas. (25694).

Os usos das circunstâncias de lugar nessa pesquisa e nesse trabalho deixam claro que o desfocamento é do Ator que, nesses casos, é autor/pesquisador responsável pela investigação.

As construções mais comuns, de desfocamento de baixo grau, não possuem esses tipos de circunstâncias, mas, nos contextos de ocorrência e com o uso do verbo no passado, pode-se pressupor um Ator:

10. Observou-se predominância de Fusarium semitectum e de Alternaria spp....(25964).

11. Avaliando somente o efeito da pré-embebição, não se verificou aumento na sincronia em relação à testemunha....(encacb). 


\section{Por último, analisou-se o problema das edificações deterioradas. (m.amb5).}

Sabe-se que o artigo de pesquisa é um texto em que se relata sobre uma pesquisa feita, por isso, os verbos ligados ao processo de fazer pesquisa (observar, verificar e analisar.) permitem pressupor um Agente, o pesquisador, responsável pelas etapas/ações do trabalho. Nota-se que esses verbos são materiais próximos dos mentais, pois se pressupõe uma reflexão, além do fazer.

Há um grupo de verbos que se comportam de maneira diferente, são eles os mentais e os verbais. Notou-se que o refraseamento possível (primeira pessoa do plural) não tem exatamente o mesmo significado, isto é, o nós parece ser impreciso, podendo se referir às pessoas de maneira geral, aos pesquisadores da área ou, até mesmo, ao autor ou aos autores do artigo.

É importante compreender o que uma determinada escolha acarreta nos significados na interação com leitor do artigo científico. Com base nos significados de natureza interpessoal, a inclusão ou exclusão do escritor e do leitor é um aspecto importante para a análise.

Os trabalhos pesquisados discutem o traço semântico humano nas construções com se. Ikeda (1980) e Neves (2000) tratam da possibilidade de inclusão de pessoas no discurso. A primeira pesquisadora sugere que a construção com se pode incluir qualquer pessoa, da mesma forma que a gente, no entanto, essa equivalência não é exata, pois essa forma inclui obrigatoriamente a primeira e a segunda pessoa, enquanto a construção com se apresenta a possibilidade, mas não a obrigatoriedade dessa inclusão. Neves (2000, p. 463) discute que as construções com se fazem parte de um conjunto de construções tipicamente genéricas, isto é, de sujeitos maximamente indeterminados, visto que todas as pessoas do discurso foram abrangidas. Para Naro (1976), as construções em que todas as pessoas foram incluídas possuem o traço grupo, nomenclatura utilizada pelo autor (op.cit.) para orações com referências genéricas e imprecisas.

Com base na observação das ocorrências do corpus, constatou-se que a maioria das construções com os processos mentais é utilizada para representar informações partilhadas entre a comunidade acadêmica, como as abaixo:

13. Sabe-se que acima de 90,00\% de frutos normais é considerado satisfatório....

14. ....hoje sabe-se que esse problema é causado pela presença da bactéria Xylella fastidiosa... (25744).

15. Quando se pensa em gestão de resíduos deve-se sempre prevalecer o bom senso.... (meioamb22).

O uso do saber e pensar com se introduz um conhecimento compartilhado trazido pela projeção. Apresentar o conhecimento como sendo algo partilhado é um recurso importante na estratégia de envolvimento que pode conferir maior peso ao ponto de vista do autor, pois não é ele sozinho que sabe ou pensa, mas sim ele e mais alguém e/ou pessoas da área de estudo. Pode-se pensar que, pelo fato de não haver referências a trabalhos e/ou pesquisadores, a proposição apresente um conhecimento partilhado que parece ser estabelecido na área, podendo incluir além do autor, o leitor (médio grau de desfocamento). Pode-se pensar, também, que esse não compartilha do conhecimento, estando, portanto, excluído. É importante observar que parece não haver obrigatoriedade de inclusão do leitor.

Assim como os processos mentais, os verbais são utilizados para representar um conhecimento partilhado na comunidade científica: 
16. Muito se fala da necessidade de preservação do meio ambiente e nas obrigações legais em que os empreendimentos devem se enquadrar, porém pouco se definem os custos que tudo isso determina. (m.amb25).

17. Muito se fala das consequências clínicas dos procedimentos odontológicos sobre o sorriso, mas pouco se avalia as suas características intrínsecas. (odrdp15.9).

18. Em paralelo, fala-se recorrentemente do aumento da receita tributária disponível nas esferas subnacionais.... (econ27).

Nas ocorrências acima, assim como outras analisadas nesta categoria, as circunstâncias contribuem para o desfocamento do participante, neste caso, Dizente (médio grau de desfocamento). Nos dois primeiros exemplos, a circunstância modo-intensidade muito representa como a informação dada é difundida e conhecida na área de estudo. Da mesma forma ocorre, em 33, com o adjunto de frequência recorrentemente.

Não há apenas ocorrências com médio grau de desfocamento, posto que o uso de circunstâncias pode limitar apenas a participação do autor:

19. Ressalta-se aqui a necessidade de acrescentar, em trabalhos dessa natureza, o tratamento sem a aplicação do elemento.... (25730).

20. Propôs-se, neste trabalho, avaliar o fluxo difusivo de potássio em três solos de texturas distintas.... (c.agral2).

21. O português tem sido considerado uma língua SVO, como já se afirmou no início deste trabalho. (Idg089).

As circunstâncias aqui, neste trabalho e no início deste trabalho (Localização - lugar) restringem a participação apenas ao autor que, nestes casos, é o Dizente dos verbos ressaltar, propor e afirmar.

\subsection{Categoria 3: SE em construções agnatas}

Nesta categoria, são analisadas as construções em que o clítico se ligado a determinados verbos acarreta um tipo de processo diferente do mesmo verbo sem se, como ocorre nos exemplos:

\section{A. Ele se encontra em São Paulo.}

B. Ele está em São Paulo.

$\mathrm{O}$ verbo encontrar, na construção acima, não tem significado material de descobrir ou achar, mas sim de estar. Neste caso, a estrutura A é agnata de B, isto é, embora possua escolhas gramaticais diferentes, ela tem o mesmo significado de B.

A relação que A e B estabelecem é de agnação. Do ponto de vista gramatical, essas escolhas são diferentes, porém, do ponto de vista semântico, Halliday (1994, p. 121) as denomina agnatas. Para a LSF, o fenômeno pode ser explicado não somente indicando como ele está estruturado, mas mostrando como ele está relacionado a outras funções da estrutura linguística, utilizando seu padrão de relações sistêmicas ou agnatas.

O conceito de agnato é importante para esta tese, pois permite explicar como um novo significado (relacional e/ou existencial) pode ser criado quando o clítico se ocorre, em determinados contextos e com certos tipos de verbos. 
Nesta pesquisa, foi constatado que, quando sem o clítico se, verbos que atuam como processos materiais, mentais ou verbais, enquanto acompanhados de $s e$, adquirem significado relacional e/ou existencial. São, portanto, entradas lexicais diferentes. De acordo com a teoria sistêmico-funcional, uma unidade semântica pode ser realizada de diferentes formas, por unidades gramaticais distintas. É o que ocorre nas construções desta categoria, por exemplo:

c. A opção pelo modelo de Dik justifica-se no fato de ser esse autor pioneiro na tentativa de propor uma teoria funcional completa, que, entretanto, ainda se acha em fase de elaboração. (Idg089).

Achar, na ocorrência acima, não tem significado mental (sinônimo de pensar) e, também não tem significado de material (sinônimo de encontrar), pois como se observa em C', com o clítico se, achar significa estar:

$C^{\prime}$. A opção pelo modelo de Dik justifica-se no fato de ser esse autor pioneiro na tentativa de propor uma teoria funcional completa, que, entretanto, ainda está em fase de elaboração. (Idg089).

O mesmo fenômeno ocorre com um conjunto de verbos dos quais alguns são discutidos nesta análise, como é o caso das construções do verbo tratar, acompanhadas de se, que não têm significado material (cuidar, alimentar, por exemplo), mas relacional, por isso são agnatas. Nas ocorrências abaixo, tratar é utilizado para definir o trabalho desenvolvido:

22. Trata-se, na verdade, de uma análise, dentro do arcabouço teórico gerativo.... (Idg103).

23. Trata-se, em linhas gerais, de uma tentativa de complexificar os pontos de vista científico e analítico-interpretativo... (25458).

24. Trata-se de uma proposta para a solução de problemas.... (eng23).

25. Trata-se de um recorte nos resultados de pesquisa realizada em Maranguape, a 27km da capital do Ceará... (m.amb58).

Nessas construções, o verbo é seguido de nomes, possui participante (Identificador) recuperável no contexto e, em geral, corresponde ao trabalho, ao artigo e à pesquisa. A relação dos participantes, estabelecida nessas orações, é Identificador e Identificado, que corresponde a uma análise, uma tentativa, uma proposta e um recorte nos resultados de pesquisa. Por serem orações identificadoras, a ordem dos participantes pode ser alterada, sem alteração do significado.

O verbo dar, quando ocorre com se, não tem significado material (oferecer, entregar, pagar, por exemplo), mas relacional, também utilizado na definição de aspectos teóricos, conforme exemplos abaixo:

26. A autonomia não se dá no âmbito da natureza reduzida ao em si de si mesmo, ou seja, enclausurada numa existência determinada. (25480).

27. Na escrita, a interação dá-se com um sujeito potencialmente ausente.... (Idg018).

28. A sistematização de classificação industrial dá-se segundo uma ou mais características dos bens e serviços produzidos.... (econl).

Há orações que são utilizadas para fazer descrições, atribuindo características a uma entidade, conforme ocorrências: 
29. Diversos moradores do bairro do Barracão pedem-nos reclamemos atenção a quem de direito para o verdadeiro estado de abandono em que se acha parte do Município. (25204).

30. Esse fenômeno [progressão referencial] acha-se no excerto abaixo. (Idg016).

31. Na mesma comissão estava presente, também, o deputado Andrade Figueira, um dos principais debatedores do projeto quando este ainda se achava na Assembléia Geral. (25348).

Nos exemplos acima, as orações atributivas são utilizadas para descrever e avaliar aspectos tratados nos artigos, representados pelos Portadores (explicação, fenômeno, parte do Município e projeto). Nota-se que os Atributos dos exemplos 44 e 45 são do tipo circunstancial (x está em a), em que estar em significa estar em, sobre, para com, acerca, ao longo, etc.

Nos artigos, as ocorrências dos verbos realizar, manifestar e estabelecer têm por função discutir aspectos teóricos, descrevendo-os como ocorrem:

32. Para o autor a "sublimação (repressiva) da sexualidade" se estabelece no contexto de uma sociedade repressiva.... (25430).

33. Essa tendência manifesta-se, também, na difusão de padrões de organização econômica e social... (meioamb013).

34. O ato de intelecção realiza-se sem cessar. É difícil dizer onde começa e onde termina o esforço intelectual. (25354).

35. Alguns trabalhos comprovam o efeito positivo da adubação orgânica sobre a produção e a qualidade... principalmente em solos de clima tropical, onde a decomposição de matéria orgânica se realiza intensamente (Silva, 2002). (ensebsn).

Pode-se notar que os verbos acompanhados do clítico se, nas ocorrências acima, possuem significado de acontecer/ocorrer, sendo que o participante Existente localiza-se à esquerda do verbo e à direita circunstâncias de lugar (em 47) e modo (em 48 e 49). Pode-se pensar que essas ocorrências são construções passivas, porém o significado seria diferente, pois em uma construção passiva, mesmo com o participante omitido (Ator, Dizente, Existente, etc.), se supõe que aquela ação foi feita por um participante humano. Para Said Ali (1966/2008, p. 116), admitir o sentido passivo é admitir a possibilidade de um agente tanto oculto como expresso.

Ao contrário das orações materiais em que um agente age sobre um objeto, o Ator age sob a Meta, as orações existenciais anunciam a existência de algo. Thompson (1996, p. 101), no caso do inglês, discute que as orações existenciais, em geral, têm o verbo ser, porém os outros verbos que comumente ocorrem são diferentes de atributivos ou identificadores. A construção mais comum é com there, que não tem uma função representacional, mas é necessária como um Sujeito.

Assim como no inglês, em português, em orações deste tipo, o falante renuncia à oportunidade de se representar nos acontecimentos. É uma característica distintiva estrutural que promove um sinal de renúncia, podendo ser visto como um recurso do autor apenas observar, em vez de participar do fluxo informacional do texto. É o caso de orações como 47 de duas maneiras - como uma construção existencial ou passiva:

47'. Para o autor a "sublimação (repressiva) da sexualidade" ocorre no contexto de uma sociedade repressiva.... 
47". Para o autor a "sublimação (repressiva) da sexualidade" é estabelecida no contexto de uma sociedade repressiva.....

Mesmo com o Agente omitido, como em 47', há um resquício de Agente, nesse caso, Ator. Isto é, pressupõe-se um Ator que está omitido porque a ação é mais importante nesse gênero do que o Agente. Por outro lado, nas construções existenciais, não se pressupõe um Agente (Ator, no caso de processos materiais, por exemplo), visto que o autor renuncia à possibilidade de se representar no texto. Esse fenômeno também ocorre nas ocorrências 48, 49 e 50 .

\section{Considerações finais}

As análises mostram que os usos do clítico se não estão somente ligados a termos sintáticos descritos tanto em livros didáticos como em gramáticas normativas, mas estão intimamente ligados ao significado que o se desempenha no contexto em que está inserido.

O arcabouço teórico e metodológico da Linguística Sistêmico-Funcional permitiu descrever e analisar os usos do se em artigos científicos produzidos em situação real de comunicação, neste caso, os artigos de pesquisa. $\mathrm{O}$ ambiente situacional e o cultural foram levados em conta na análise das escolhas gramaticais feitas nos textos.

O instrumento computacional WordSmith Tools (SCOTT, 2008) possibilitou o trabalho com uma grande quantidade de textos, fornecendo os contextos em que a palavra de busca se ocorre, contribuindo para um estudo sistemático e minucioso de cada ocorrência e dos contextos em que ocorrem.

Foram encontrados três padrões de uso desse clítico que ocorrem em três tipos diferentes de construções: médias, com desfocamento de participante e agnatas. Nas primeiras não se pressupõem um participante explícito; a oração parece ocorrer sozinha, sem um participante com caráter de Agente. As construções com participante desfocado, por sua vez, podem ser de alto grau quando todos os participantes estão desfocados, ou seja, um tipo de desfocamento mais geral e, portanto, mais genérico; de médio grau ocorrendo quando a comunidade acadêmica está desfocada, supondo-se que o autor e o leitor, por fazerem parte dessa comunidade, também estão desfocados e, por fim, o de baixo grau que ocorre em orações em que a participação do autor do artigo ou de um pesquisador citado é pressuposta pelo contexto.

As construções agnatas são realizadas por processos materiais que, ocorrendo em contextos com o clítico se, possuem significados diferentes de contextos sem se funcionando como processos relacionais e/ou existenciais.

Espera-se que esta pesquisa possa contribuir para o ensino de escrita acadêmica ou, até mesmo, adaptado para o uso nas escolas de Ensino Fundamental e Médio, propondo uma reflexão dos usos do se com base em exemplos reais de gêneros conhecidos pelos alunos. Pretende-se, futuramente, elaborar um material com foco na escrita acadêmica para alunos de graduação e pós-graduação.

\section{Referências}

BAGNO, M. A “subversão herética” do ensino de língua. In: Bagno, M. Dramática da Língua Portuguesa: tradição gramatical, mídia e exclusão social. São Paulo: Loyola. 2000, pp. 219250.

BERBER SARDINHA, T. Linguística de Corpus. Barueri-SP: Manole, 2004. 
CAFFAREL, A. A systemic functional grammar of french. Londres: Continuum, 2006.

CAMACHO, R. G. Construções de voz. In: Abarirre, M. B. \& Rodrigues, S. C. A. (org). Gramática do português falado. v. 8, pp. 227-316. Campinas: Editora Unicamp, 2002.

CAMACHO, R. G. Em defesa da categoria de voz média no Português. D.E.L.T.A., v. 19.1, pp. 91-122, 2003.

CEGALlA, D. P. Novíssima gramática da língua portuguesa. São Paulo: Editora Nacional, 1996.

CINQUE, G. On si constructions and the theory of Arb. Linguistics inquiry. V. 19, 4, 1988, pp. 521-581.

CUNHA, C. \& CINTRA, L. Nova gramática do português contemporâneo. Rio de Janeiro: Nova Fronteira, 1985.

DE MIGUEL, E. El aspecto em la sintaxis del español. Madri: Ediciones de la Universidad Autônoma de Madri, 1992.

HALLIDAY, M.A.K. An Introduction to Functional Grammar. London: Edward Arnold, 1985.

HALLIDAY, M. A. K. \& MARTIN, J. R. Writing sciece: literacy and discursive power. London: Falmer, 1993.

HALLIDAY, M. A. K. An introduction to Functional Grammar. London: Edward Arnold, 1994.

HALLIDAY, M. A. K. The language of science. New York: Continuum, 2004.

HALLIDAY, M. A. K. \& MATTHIESSEN, C. An introduction to Functional Grammar. London: Edward Arnold. Third Edition, 2004.

HAWAD, H. F. Tema, sujeito e agente: a voz passiva portuguesa em perspectiva sistêmicofuncional. Tese de Doutorado. PUC-RJ, 2002.

IKEDA, S. N. A função do pronome se. Dissertação de Mestrado. PUC-SP, 1977.

MONTEIRO, J. L. A questão do se. In: Monteiro, J. L. Pronomes pessoais: subsídios para uma gramática do português do Brasil. Fortaleza, EUFC, 1994.

MORAIS, F. B. C. Entre alhos e bugalhos: os diferentes usos do clítico SE na escrita acadêmica. Tese de Doutorado. PUC-SP, 2013

NARO, A. J. The genesis of the the reflexive impersonal in Brazilian Portuguese: a study in syntactic change as a surface phenomenon. Language 52:4. pp. 779-810, 1976.

NEGRONI, M. M. G. La construcción media com se. Filologia. V.29.pp.58-81, 1996.

NEVES, M. H. M. Gramática de usos do Português. São Paulo: Editora Unesp, 2000.

NUNES, J. Se apassivador e se indeterminador: o percurso diacrônico no português brasileiro. Caderno de Estudos Linguísticos, V. 20, pp. 33-59, 1991.

ROCHA LIMA, C. H. Gramática normativa da língua portuguesa. Rio de Janeiro: José Olympio Editora, 2002.

RUWET, N. Les constructions pronominales neutres et moyennes. Théorie syntaxique et syntaxe du français. Paris: Seuil, 1972.

SAID ALI, M. Dificuldades da língua portuguesa. Rio de Janeiro: Biblioteca Nacional. $1^{\text {a }}$ ed. 1966, 2008. 
SCOTT, M. R. Wordsmith Tools v. 5. Software for text analysis. Oxford: Oxford University Press, 2008.

SHIBATANI, M. Passives and related constructions: a prototype analysis. Language 61:4. pp. 821-848, 1985

SUÑER, M. Las passives con se impessoal y la legitimación de las categorias vacías. In: Lopes, C. S. 2002. Las construciones com se. Madri: Visor libros, 2002.

SWALES, J. M. Genre analysis - English in academic and research settings. Cambridge University Press, 1990.

SWALES, J. M. \& FEAK, C. B. Academic writing for graduate students. Michigan: The University of Michigan Press, 1999.

THOMPSON, G. Introducing functional grammar. London: Arnold, 1996. 